\title{
Transcanal Tympanoplasty with Cartilage-Perichondrium Composite Graft
}

\author{
Ceki Paltura', Şaban Çelebi', Ömer N. Develioğlu², Tzemal Chatzi', Murat Topak², M. Haluk Özkul', Mehmet Külekçi \\ ${ }^{1}$ Clinic of Otolaryngology, Haseki Training and Research Hospital, İstanbul, Turkey. \\ ${ }^{2}$ Clinc of Otolaryngology, Gaziosmanpaşa Taksim Training and Research Hospital, İstanbul, Turkey
}

\section{ABSTRACT}

Objective: The aim of this study was to evaluate the results of transcanal tympanoplasty surgery performed using a cartilage-perichondrium composite graft.

Methods: Forty patients were included in this study. Their tympanic membrane (TM) perforations were limited to one quadrant, and there was a longterm hearing loss. All patients who had undergone surgery had a dry ear for at least 6 months. All patients had undergone transcanal tympanoplasty surgery with the cartilage-perichondrium composite graft, and the success of the surgery was evaluated by physical examination and audiological evaluation after 6 months of surgery.

Results: After the surgery, 35 (87.5\%) patients had an intact tympanic membrane. There was a statistically significant decrease in the air-bone gap of patients' hearing levels (mean preoperative hearing level, $21.29 \mathrm{~dB}$; mean postoperative hearing level, 13.23 dB; $p<0.01$ ).

Conclusion: Cartilage-perichondrium composite graft usage with transcanal tympanoplasty surgery takes shorter time than other methods. The procedure shows less morbidity because of no disruption of the normal anatomy, absence of a big and visible incision, and no elevation of the tympanometal flap. Also, the mean hospitalization time is lesser; we had similar success with the standard tympanoplasty procedures. (JAREM 2015; 5: 107-9)

Keywords: Cartilage, perichondrium, tympanic membrane

\section{INTRODUCTION}

A common cause of otitis media is the permanent perforation of the tympanic membrane (TM). This situation may lead to problems such as hearing loss and frequent otorrhea in patients. First, Berthold (1) tried to surgically repair a TM perforation with a skin graft in 1878. Later, Zöllner (2) and Wulstein (3) identified materials that could be used as grafts and methods, respectively. Today, the temporalis muscle fascia, perichondrium, and cartilage with perichondrium are most commonly used as graft materials (4).

The overall aim of tympanoplasty is to prevent infection and discharge in the middle ear and restore hearing by TM perforation repair. Depending on the pathology in the middle ear, this operation can be performed with or without mastoidectomy. Tympanoplasties are traditionally classified as medial (underlay) or lateral (overlay). The landmark for this classification is the annulus tympanicus (AT). The operation is named according to the placement of the graft medial or lateral to the AT.

The aim of this study is to evaluate the results of overlay cartilage perichondrium composite graft tympanoplasty with the transcanal approach.

\section{METHODS}

This study was conducted by retrospectively examining the patient records. Ethics committee approval was obtained from the Haseki Training and Research Hospital (152/12.11.2014). The ages of patients ranged from 15 to 55 years. TM perforations of the operated patients were limited to a single quadrant. They had mild hearing loss and did not have otorrhea within the last 6 months. Each patient filled the required information form before the operation, and complications that may occur in the postoperative period were explained to them. Audiological tests and physical examination data were evaluated in the $6^{\text {th }}$ postoperative month.

The operation was performed under general anesthesia. Tragal cartilage, covered on one side with the perichondrium, which is as large as the perforation and $0.5 \mathrm{~mm}$ at the thickest point was used as the graft material. The excess perichondrium was laid on the TM. Audiological tests and physical examinations were performed 6 months after the operation. Airway gains of the patients and air-bone gaps were evaluated by calculating the average of the hearing values of patients at $500 \mathrm{~Hz}, 1000 \mathrm{~Hz}$, and $2000 \mathrm{~Hz}$.

\section{Statistical Analysis}

Statistical analyses of the averages of pre- and postoperative airbone gap were assessed using the paired t-test.

\section{RESULTS}

Forty patients were included. Of these, $16(40 \%)$ were females and $24(60 \%)$ were males. Eighteen (45\%) patients were operated in the right ear and $22(55 \%)$ in the left ear. Post-surgery, the TM perforation was closed in $35(87.5 \%)$ patients. The perforation could not be completely closed in $3(7.5 \%)$ patients, but more than $50 \%$ closing occurred in the perforation in comparison to preoperative sizes. The perforation size did not change in 2 (5\%) patients. Otorrhea occurred in the early postoperative period in these 2 patients, and the graft was discarded. An average of 9.4 $\mathrm{dB}$ (SD: \pm 5.20859 ) airway gain was achieved in patients whose perforations were closed. From the results of the statistical analysis, a significant gain was achieved in the air-bone gap of the patients $(p<0.01)($ Table 1). 


\section{DISCUSSION}

Tympanoplasty is one of the most frequently performed surgical procedures for the middle ear. The primary aim in this surgery is to create an ear free of infections and discharge, and if successful, to provide a positive gain in the hearing capacity of the patient. For this purpose, many autologous materials such as skin, venous vein wall, perichondrium, oil, and dura have been, and are still, used (5). Each material has a specific success rate and its own limitations. The most widely used material is the temporalis muscle fascia. Even though it has a success rate of between $80 \%$ and $95 \%$, it may cause some problems during the postoperative period. A larger incision is made in order to remove the graft, the middle ear cavity and the anatomy of the external auditory canal are temporarily deformed with the elevation of the tympanomeatal flap, and more stringent postoperative care is required (6). This process extends the total duration of surgery and the patients become susceptible to infection. During the operation, the malleus head or the ossicular chain can be damaged. In addition, it may lead to additional morbidity in cases where revision surgery is required due to the deformation of normal anatomy, albeit minimal (7). After this operation, redressing is performed more frequently in patients and the time to return to normal life increases with additional hospitalization time.

Cartilage, perichondrium and fascia originate from mesenchymal tissue. Cartilage can be manipulated more easily than the fascia and has long-term viability, and this accelerates healing of TM by way of epithelialization in the postoperative period $(8,9)$. Supporting of the cartilage with perichondrium that is mechanically more stable during healing immobilizes the perichondrium, and until revascularization, prevents failure in early periods by preventing hernia into the middle ear cavity (10). Shrinking of the perichondrium is also minimized thanks to the cartilage junction (10). The grafts taken from the temporalis muscle fascia can be more easily lateralized due to the fixation with adhesion in the recovery period (10).

One of the tympanoplasties that can be performed through the transcanal is fat tympanoplasty made using the fat taken from the ear lobule. Grafts are placed through the transcanal in this method. However, it was observed that in the conducted studies no successful results were obtained in perforations covering more than $30 \%$ of the pars tensa $(11,12)$. That this operation also reached functionally similar conclusions has been published,

Table 1. Preoperative and postoperative air-bone gap averages of the patients

\begin{tabular}{|l|c|c|}
\hline Mean & $\begin{array}{c}\text { Preoperative } \\
\text { A-B gap }\end{array}$ & $\begin{array}{c}\text { Postoperative } \\
\text { A-B gap }\end{array}$ \\
\hline $\mathrm{SD}$ & 21.29 & 13.23 \\
\hline $\mathrm{SEM}$ & 6.46 & 7.15 \\
\hline $\mathrm{n}$ & 1.09 & 1.21 \\
\hline $\mathrm{p}<0.01$ & 35 & 35 \\
\hline SD: standard deviation; SEM: standard error of the mean; n: number
\end{tabular}

but the operation time was longer than the cartilage tympanoplasty method (13). In addition, the perforation size should be smaller to the size of the transcanal cartilage tympanoplasty.

Many publications have indicated that the success rate is between $80 \%$ and $85 \%$ when the operation is performed in accordance with standard techniques. In addition, some surgeons say that success can reach $95 \%$. Closure of the TM perforation, stopping of the discharge, and improvements in hearing can be considered as success criteria after surgery. While success is generally achieved in the first two criteria, hearing results are not expected most of the time. Our primary goal was to also reach the middle ear cavity without infection with our applied technique. The TM perforation was fully closed in $87.5 \%$ of patients, and in this criterion, we achieved similar results to the published literature. More than $50 \%$ of the graft adhered in 3 of the $5(12.5 \%)$ patients in whom the perforation could not be closed. In two patients, the grafts were discarded because of infection.

Cartilage that is thicker in comparison to the fascia may negatively affect hearing or might fail more in terms of reducing hearing loss. However, in vitro studies have shown that islands of cartilage under $0.5 \mathrm{~mm}$ have no difference in terms of transmission compared to the fascia (14). Therefore, the thickness of the cartilage used in the operation was not to be more than $0.5 \mathrm{~mm}$. In audiological examinations of the patients, an airway gain of 9.4 $\mathrm{dB}$ was detected in average hearing frequencies $(500 \mathrm{~Hz}, 1000$ $\mathrm{Hz}$, and $2000 \mathrm{~Hz}$ ). A similar result was also reported in the study by Milewski (9). Similar ratios were also obtained in the study by Karaman et al. (15). Ben Gamra et al. (16) anatomically and audiologically compared the patients undergoing cartilage and fascia tympanoplasty. In this 380-patient study, they found that there were no anatomical and functional differences between the two groups. Based on these similar results, they suggested that using cartilage was the first choice in tympanoplasties (16).

In the study by Haksever et al. (6), while the operating time in butterfly cartilage tympanoplasty was measured as $29.9 \pm 5.38$ min, the underlay tympanoplasty procedure was measured to take $58.9 \pm 12.1 \mathrm{~min}(6)$. In our study, the operation time was similar because of the technical similarities. When operation time is taken into account, it is thought that the operation could be performed in selected cases with only local anesthesia. Because the temporalis muscle fascia is not removed, a mastoid bandage is not applied and the canal is closed with a patch by placing buffer gas only in the outer ear canal. In this way, the need for dressing of the patient decreases and the postoperative hospitalization time is reduced. Thus, return to normal life for patients can be achieved faster. The risk of surgical morbidity is lower because the ossicular chain does not come in view during the operation and the normal anatomy is not deformed. Because the cartilage is a more stable material and ensures the vitality of the perichondrium with diffusion, it does not cause graft complications such as lateralization or herniation in the early period. We advise the use of this method as the first choice because it has fewer surgical complications, it is more successful in the early postoperative period, and it increases the confidence of young surgeons, particularly new ones entering the profession. 


\section{CONCLUSION}

Tympanoplasty performed using a cartilage-perichondrium composite graft by the transcanal method is faster than other methods, requires less surgery, and has lower postoperative morbidity rates. In addition, hospitalization time is shorter, and the success rates in our study were similar to those using the standard methods. Therefore, it is a treatment method that can be applied to patients with a quadrant not bigger than TM, with air-bone gap not more than $30 \mathrm{~dB}$ in hearing, and without any pathology in the mastoid cavity or ossicular chain. Future studies that can be compared with this paper and other methods can be investigated.

Ethics Committee Approval: Ethics committee approval was received for this study from the ethics committee of Haseki Training and Research Hospital (152/12.11.2014).

Informed Consent: Written informed consent was obtained from patients who participated in this study.

Peer-review: Externally peer-reviewed.

Author Contributions: Concept - C.P., M.K.; Design - M.T., Ö.D.; Resources - T.C., M.H.Ö.; Materials - Ş.Ç.; Analysis and/or Interpretation - C.P.; Literature Search - C.P.; Writing Manuscript - C.P.; Critical Review - C.P.

Conflict of Interest: No conflict of interest was declared by the authors.

Financial Disclosure: The authors declared that this study has received no financial support.

\section{REFERENCES}

1. Berthold E. About myringoplasty. Wien Med Blätter 1878; 26: 627-39.

2. Zöllner $F$. The principles of plastic surgery of the sound conducting apparatus. J Laryngol Otol 1995; 69: 657-9.

3. Wulstein HL. Funktionelle Operationen im Mittelohr mit Hilfe des frein Spaltlappentransplantates. Arch Otorhinolaryngol 1952; 16: 422-35. [CrossRef]
4. Sheehy JL, Glasscock ME. Tympanic membrane Grafting with temporalis fascia. Arch Otolaryngol 1967; 86: 391-402. [CrossRef]

5. Sheehy JL, Anderson RG. Myringoplasty: a review of 472 cases. Ann Otol 1980; 89: 331-4. [CrossRef]

6. Haksever M, Akduman D, Solmaz F, Gündoğdu E. Inlay butterfly cartilage tympanoplasty in the treatment of dry central perforated chronic otitis media as an effective and time-saving procedure. Eur Arch Otorhinolaryngol 2015; 272: 867-72. [CrossRef]

7. Raj A, Sayal A, Rathore PK, Meher R. Sutureless tympanoplasty using acellular dermis. Am J Otolaryngol 2011; 32: 96-9. [CrossRef]

8. Levinson RM. Cartilage-perichondrial composite graft tympanoplasty in the treatment of posterior marginal and attic retraction pockets. Laryngoscope 1987; 97: 1069-74. [CrossRef]

9. Milewski C. Composite graft tympanoplasty in the treatment of ears with advanced middle ear pathology. Laryngoscope 1993; 103 : 1352-6. [CrossRef]

10. Borkowski G, Sudhoff H, Luckhaupt H. Autologous perichondriumcartilage graft in the treatment of total and subtotal perforations of the tympanic membrane. Laryngorhinootologie 1999; 78: 68-72. [CrossRef]

11. Konstantinidis I, Malliari H, Tsakiropoulou E, Constantinidis J. Fat myringoplasty outcome analysis with otoendoscopy: who is the suitable patient?. Otol Neurotol 2013; 34: 95-9. [CrossRef]

12. Kim DK, Park SN, Yeo SW, Kim EH, Kim JE, Kim BY, et al. Clinical efficacy of fat-graft myringoplasty for perforations of different sizes and locations. Acta Otolaryngol 2011; 131: 22-6. [CrossRef]

13. Wang WH, Lin YC. Minimally invasive inlay and underlay tympanoplasty. Am J Otolaryngol 2008; 29: 363-6. [CrossRef]

14. Bernal-Sprekelsen M, Romaguera Lliso MD, Sanz Gonzalo JJ. Cartilage palisades in type III tympanoplasty: anatomic and functional long-term results. Otol Neurotol 2003: 24: 38-42. [CrossRef]

15. Karaman E, Yılmaz S, Öğreden Ş, Acıoğlu E, Enver Ö. Tragal Kıkırdak Timpanoplasti Sonuçlarımız. Cerrahpaşa Tıp Dergisi 2007; 38: 43-5.

16. Gamra OB, Mbarek C, Khammassi K, Methlouthi N, Ouni H, Hariga I, et al. Cartilage graft in type I tympanoplasty: audiological and otological outcome A. Eur Arch Otorhinolaryngol 2008; 265: 739-42. [CrossRef] 